УДК: 338.43

КУРБАНОВ КАЗБЕК КЕРИМОВИЧ

к.э.н., ведущий научный сотрудник ФГБУН «Институт соииально-экономических исследований ДНЦ $\rho$ АН», e-mail:kkurbanov@mail.ru

АТАЕВА ВАЗИПАТ ХИЗРИЕВНА

к.э.н., доцент кафедры философии и истории ФБГБОУ ВО «Дагестанский государственный медицинский университет», e-mail:kkurbanov@mail.ru

ГАСАНОВА АИДА ДЖИГАНОВНА к.э.н., доиент, преподаватель кафедры 48 Военного Университета МО РФО e-mail: jiganovna@mail.ru

ЭМИНОВА ЭЛЬНАРА МИГАЖИДИНОВНА к.э.н., доцент, доцент кафедры «Экономика и управление в АПК» ФБГБОУ ВО «Дагестанский государственный аграрный университет имени М.М. Джамбулатова», e-mail: e-eminova@mail.ru

\title{
СОВРЕМЕННЫЕ ПРОБАЕМЫ ЭФФЕКТИВНОГО РАЗВИТИЯ АПК И ПУТИ ИХ РЕШЕНИЯ (НА ПРИМЕРЕ СУБЪЕКТА СКФО)
}

\begin{abstract}
Аннотауия. Шель работы заключается в исследовании проблем, сдерживающих эффективное развитие АПК проблемного региона и разработке основных мероприятий, позволяющих существенно увеличить объемы и улучшить качество производимой сельскохозяйственной продукции, обеспечить ее хранение и переработку, снизить напряженность с занятостью населения [7]. Это, в свою очередь, позволит успешно решить проблему инновационного развития на основе повышения эффективного использования ресурсного потенциала и конкурентоспособности конечной продукции АПК. Методологией проведения работы послужили труды отечественных и зарубежных ученых в области формирования организащионно-экономического механизма развития агропромышленного комплекса, организационно-экономических отночений в сферах производства сельскохозяйственной продукиии, переработки, финансово-кредитного обслуживания, реализации продукиии и др. В работе использованы системный анализ, общенаучные логические приемы и методы исследования. Результаты работы. Особенностью подструктур АПК является тесная взаимосвязь пищевой и перерабатывающей промышленности с сельскохозяйственным производством. При этом, по результатам исследований, производственные данные отрасли пищевой промышленности развиваются далеко не всегда на основе переработки местного сырья, что усиливает их технологическую оторванность от сельскохозяйственного производства [6]. В связи с чем возникает необходимость создания интегрированных агропромышленных хозяйственных структур на региональном уровне. Область применения результатов. Результаты проведенного исследования могут быть использованы органами региональной власти при разработке комплексных программ регионального развития и формирования агропромышленных структур, опирающихся на всестороннюю оценку конкурентных преимуществ региона, его природно-климатических условий, сложившуюся структуру производства и специализацию в агропромышленных связях [8]. Выводы. Структурные преобразования сельскохозяйственных и перерабатывающих предприятий в проблемном регионе не только приостановили позитивные сдвиги в проиессах агропромышленной интеграции, но и разрушили все то, что было создано ранее. СDормирование агропромышленных предприятий в регионе в современных рыночных условиях хозяйствования представляется жизненно важной проблемой, решение которой оказывает самое непосредственное влияние на экономический рост и повышение уровня жизни населения.
\end{abstract}

Ключевые слова: проблемный регион, агропромышленная интеграция, модернизачия, сельское хозяйство, конкурентоспособность. 
KURBANOV KAZBEK KERIMOVICH $\rho_{h}$. D. in Economics, leading researcher at the Federal state budgetary INSTITUTION "Institute of socio-economic research, Dagestan scientific center $R A S$ », e-mail: kkurbanov@mail.ru

ATAEVA VAZIPAT KHIZRIEVA

Ph. D. in Economics, associate Professor of the Department of philosophy and history of Dagestan state medical University», e-mail:kkurbanov@mail.ru

HASANOVA AIDA DZHIGANOVNA

Ph.D. in Economics, Associate Professor, Associate Professor, Department of 48 Military University of the Russian Federation e-mail: jiganovna@mail.ru

EMINOVA ELNARA MIGAZHIDINOVNA

$\rho_{h D}$ in Economics, Associate $\rho_{\text {rofessor, Associate }}$ Professor, Department of Economics and Management in the Agro-Industrial Complex, Dagestan State Agrarian University named after M.M. Dzhambulatova, e-mail:e-eminova@mail.ru

\title{
MODERN PROBLEMS OF EFFECTIVE DEVELOPMENT AGRO-INDUSTRIAL COMPLEX AND WAYS TO SOLVE THEM (ON THE EXAMPLE OF THE SUBJECT OF THE NORTH CAUCASUS FEDERAL DISTRICT)
}

\begin{abstract}
The purpose of the work is to study the problems that hinder the effective development of the agro-industrial complex of the problem region and to develop the main measures that will significantly increase the volume and improve the quality of agricultural products, ensure their storage and processing, and reduce the tension with the employment of the population [7]. This, in turn, will allow us to successfully solve the problem of innovative development by increasing the effective use of resource potential and competitiveness of the final products of agriculture. The methodology of the work was the works of domestic and foreign scientists in the field of formation of the organizational and economic mechanism of development of the agro-industrial complex, organizational and economic relations in the fields of agricultural production, processing, financial and credit services, product sales, etc.the work used system analysis, General scientific logical techniques and research methods. Result of work. A feature of the substructures of the agro-industrial complex is the close relationship of the food and processing industry with agricultural production. At the same time, according to research results, the production data of the food industry are not always developed on the basis of processing of local raw materials, which increases their technological isolation from agricultural production [6]. In this connection, there is a need to create integrated agro-industrial economic structures at the regional level. The scope of the results. The results of the study can be used by regional authorities in the development of comprehensive programs for regional development and the formation of agro-industrial structures, based on a comprehensive assessment of the competitive advantages of the region, its natural and climatic conditions, the existing structure of production and specialization in agro-industrial relations [8]. Summary. Structural transformations of agricultural and processing enterprises in the problem region not only stopped positive changes in the processes of agro-industrial integration, but also destroyed everything that was created earlier. The formation of agro-industrial enterprises in the region in modern market conditions of management is a vital problem, the solution of which has a direct impact on economic growth and improving the standard of living of the population.
\end{abstract}

Keywords: problem region, agro-industrial integration, modernization, agriculture, competitiveness.

Введение. Новый этап в развитии агропродовольственного комплекса связан с усилением мер государственной поддержки: на правительственном уровне принят ряд законодательных актов, свидетельствующих о возрождении внимания к аграрному сектору и проблемам продовольственного обеспечения. 
Одной из проблем решения негативных тенденций на продовольственном рынке страны является отставание темпов роста производства сельскохозяйственного сырья от темпов роста пищевой промышленности [5]. В прошлые годы в стране и ее регионах были допущены значительные перекосы в структурной и инвестиционной политике, что привело к серьезным нарушениям пропорциональности и сбалансированности между сферами и отраслями АПК. Недостаточное развитие перерабатывающих отраслей, производственной инфраструктуры комплекса и системы реализации приводят к огромным потерям продукции сельского хозяйства. Во многих регионах не хватает мощностей по переработке и хранению сельскохозяйственной продукции, они нерационально размещены по территории, их технический уровень не всегда соответствует современным требованиям, не до конца отработаны вопросы сбыта сельскохозяйственной продукции. Выпуск качественной продукции, удовлетворяющей запросам потребителей по структуре и цене, снижение объемов импорта на деле должны стать важными задачами экономического развития современной России. Следует всерьез задействовать имеющиеся в стране и в ее регионах потенциальные ресурсы импортозамещения [9]. К решению задачи импортозамещения следует подходить комплексно, учитывая все факторы и особенности страны, а также современные тенденции международного разделения труда. Необходима продуманная, научно обоснованная программа по замещению импортного продовольствия, в которой должен доминировать экономический, а не политический аспект.

Вместе с тем определенные достижения в развитии собственного производства имеются. По целому ряду продуктов питания Россия сейчас полностью обеспечена внутренним производством - это мука, макароны, сахар. Мясо птицы почти не завозится благодаря развитию собственного птицеводства. Внутреннее производство уже обеспечивает потребности страны практически на 85 \% по растительному маслу, мясным консервам, кондитерским изделиям [9].

Методы исследования. Регионы России в силу своих природных и других потенциальных возможностей должны занять свое место в решении продовольственной проблемы по объемным, качественным и ценовым показателям [8]. Особая роль отводится Южному и СевероКавказскому федеральным округам [9].

АПК является составной частью и одним из основных системообразующих элементов экономики округа. Регионы СКФО обладают огромным потенциалом в развитии сельского хозяйства. Чтобы его реализовать, необходимо сконцентрировать усилия в четко определенных стратегических направлениях. Это прежде всего развитие садоводства и виноградарства, развитие мясного скотоводства, в том числе овцеводства.

В субъектах РФ, входящих в состав СКФО, перерабатывающая промышленность занимает от 2,7 \% (Чеченская Республика) до 14,2 \% (Кабардино-Балкарская Республика). В СКФО в 2018 году произвели сельскохозяйственной продукции на сумму 449,5 млрд руб. $[8,9,10]$.

Основная доля производства сельскохозяйственной продукции приходится на Ставропольский край -45 \%. Второе место занимает Республика Дагестан - 25,4 \%. Наименьший вклад приходится на Республику Ингушетия - 1,5\%. Анализ динамики и сложившейся отраслевой структуры АПК СКФО по основным показателям свидетельствует о том, что сельское хозяйство сохраняет свою ведущую роль в экономике округа [14]. В СКФО сосредоточено основное поголовье овец и коз (1-е место среди округов РФ). Большое значение имеет тонкорунное овцеводство. В регионе заготавливается большая часть тонкой шерсти РФ.

Как один из крупнейших регионов Северного Кавказа Республика Дагестан занимает особое место в обеспечении продовольственной безопасности страны. Рассматривая производство продукции по категориям хозяйств в АПК Республики Дагестан, можно отметить, что большая часть произведенной продукции, как в начале 2017 года, так и в конце, принадлежит хозяйствам населения (79,3 и 72,5 \% соответственно), однако прослеживается тенденция стабильного уменьшения производства сельскохозяйственной продукции в личных подсобных хозяйствах в пользу роста производства в сельскохозяйственных организациях (10,2 и 14,1\%) и крестьянских фермерских хозяйствах (10,5 и 13,4 \% соответственно) [1].

В структуре производства основных видов сельхозпродукции следует, что незначительно выросло производство зерна в сельхозорганизациях и КФХ (32 \% и $25 \%$ соответственно). Производство картофеля в подавляющем объеме (96-98 \%) находится в хозяйствах населения, так же как и овощей (95-97 \%), плодов и ягод (88-98 \%). Производство винограда приблизи- 
тельно одинаково в сельхозорганизациях и хозяйствах населения (46-48 \%). В производстве продуктов животноводства, напротив, доля хозяйств населения неуклонно падает (с 77,8 \% до $58,5 \%$ ) и растет в сельхозорганизациях (почти в 3 раза) и КФХ (с 14 до 19,7 \%). Производство яиц стабильно и существенно растет в КФХ (в 4 раза) и немного уменьшается в сельхозорганизациях и ЛПХ населения (на $23 \%$ и 10 \% соответственно). В производстве шерсти также уверенно растет доля КФХ (рост в два раза) и несущественно сельхозорганизаций (16 \%), в то время как в ЛПХ наблюдается стабильный спад (на 40 \%) [2, 3].

Валовые сборы основных сельхозкультур за рассмотренный период стабильно увеличивались, и рост с 2010 по 2017 год составил: зерно - на $90 \%$, подсолнечник - в 2,5 раза, картофель - на $28 \%$, овощи - на $49 \%$, плоды и ягоды - на $56 \%$, виноград - на $32 \%$. При этом рост валовых сборов произошел не только из-за расширения посевных площадей, но и в результате повышения урожайности, что наблюдается по всем перечисленным культурам. Показатели валового сбора в разрезе зерновых и зернобобовых культур показывает рост пшеницы, ячменя, проса, риса (в 2,6 раза, 77 \%, в 2,6 раза соответственно) при росте урожайности за период. По таким культурам, как рожь, овес, кукуруза на зерно, показатели за период практически оставались на одном уровне $[1,2]$.

Поголовье скота во всех категориях хозяйств до 2017 года стабильно увеличивалось, в 2017 году наметилось небольшое уменьшение поголовья КРС и овец и коз $(1 \%)$. По категориям хозяйств в поголовье КРС ведущая роль принадлежит хозяйствам населения (76 \%), далее КФХ (13\%). Овцы и козы преобладают в КФХ (45 \%), сельхозорганизациях (30\%).

На основании анализа структуры АПК РД в сфере обрабатывающих производств можно сделать вывод о том, что агропромышленный комплекс выпускает продукцию невысоких переделов [6]. Сегодня в Дагестане практически нет хранилищ для овощей и фруктов, а также не функционирует система их предпродажной подготовки, в том числе упаковки и фасовки. Такой подход лишает рынки страны экологически чистой отечественной продукции. И в свою очередь российский потребитель не получает качественной продукции в надлежащем состоянии. Поэтому региональные аспекты развития пищевой и перерабатывающей промышленности нашей республики заслуживают тщательного рассмотрения с целью выявления проблем и перспектив развития АПК РД $[6,8]$.

Самым главным отрицательным фактором является износ основных производственных фондов, который составляет в целом более 50 \%, а по подотраслям на частных предприятиях более 70 \%. Данный негативный аспект связан с тем, что после всех основных расходов предприятий снижается уровень оборотных средств, которых недостаточно для проведения технологического перевооружения и обновления оборудования. Поэтому показатель обновления основных фондов едва достигает $1 \%$, в то время как его норматив составляет не менее $10 \%$.

Устаревшие производственные мощности перерабатывающих предприятий не в состоянии осуществить их полную загрузку и увеличить выработку необходимой пищевой продукции, что, в свою очередь, и приводит к большим потерям сельскохозяйственного сырья.

Еще к одному негативному фактору можно отнести неразвитость рыночной инфраструктуры, которая прогрессирует в результате недостаточного притока инвестиций в регион. Такое положение дел коренным образом снижает конкурентоспособность продукции АПК республики. В связи с чем остается крайне низким использование перерабатывающей промышленностью собственной сырьевой базы. Так, например, всего менее 1 \% сбора местных овощей поступает на промышленную переработку, в то время как по РФ эта цифра достигает $20 \%$. Перерабатывающими предприятиями республики перерабатывается всего 12 \% производимого молока и $10 \%$ мяса.

На сегодняшний момент следует отметить, что местными производителями вырабатывается недостаточно пищевых продуктов для реальных потребностей местного населения. Этот недостаток покрывается за счет ввоза продовольственных товаров из других регионов страны, что сопровождается завышением отпускной цены потребителю в связи с транспортными расходами. В связи с этим крайне актуальной становится проблема обеспечения продовольственной безопасности Дагестана, которая является гарантией стабильного удовлетворения потребностей населения в продуктах питания [3, 4].

Приведем несколько фактов. В 2017 году переработкой плодоовощного сырья занималось 
11 предприятий, производственная мощность которых позволила переработать лишь 6,5 тыс. тонн плодов и 2,3 тыс. тонн овощей. А также было выпущено 29,9 муб. различной плодоовощной консервной продукции. По сравнению с 2016 годом производство консервной продукции возросло на 20,5 \%. Из всего ассортимента выпускаемой продукции 79,5 \% составляют соки, $14,8 \%$ овощные консервы, 2 \% томатная паста, $1,6 \%$ компоты, $0,5 \%$ детское питание, 0,5\% повидло, 1,1 \% варенье. Тут следует дополнить, что отсутствие в республике промышленного производства сухофруктов и замороженных плодов и овощей также негативно влияет на объем переработки плодоовощного сырья $[12,13]$.

Консервные заводы республики также сталкиваются с проблемой по закупке достаточных объемов сырья. И главная причина в том, что основной объем плодов и овощей производит частный сектор. Сложность заключается в невозможности заключения предварительных контрактов о поставках сырья, что, в свою очередь, не позволяет сельскому населению иметь заинтересованность в выращивании плодоовощной продукции технических сортов в больших объемах, так как, было сказано выше, слаборазвитая инфраструктура рынка в республике не позволит вовремя и по приемлемой стоимости реализовать продукцию.

Поэтому в основе решения проблем интеграционных процессов развития пищевой перерабатывающей промышленности должна лежать предпринимательская организация внутрихозяйственных отношений в системе регионального АПК, а также создание рыночной инфраструктуры, которая могла обеспечить функциональные связи в области маркетинговой службы, инвестиционных, инновационных, расчетно-финансовых, факторинга, консалтинга; формирование информационных центров по развитию эффективных форм предпринимательства в области лизинга агросервисных предприятий и т. д. Необходимо стимулировать внутрихозяйственные связи на всех уровнях на основе полной экономической самостоятельности и ответственности. По окончании должен быть выработан внутрихозяйственный механизм со всеми его предпринимательскими элементами и рыночными рычагами.

Сегодня очень важно содействие всех субъектов предпринимательской агропромышленной интеграции к укреплению системообразующих направлений АПК РД, которые должны привести к переходу к новым формам агробизнеса, а это: создание ассоциаций фермеров, предпринимателей на отраслевой и межотраслевой основе; создание сильного мотивационного механизма, охватывающего как вертикальные, так и горизонтальные связи, что позволит подключить к решению стратегических и тактических вопросов развития экономики все субъекты АПК; усиление их заинтересованности в соблюдении пропорций в распределении валового дохода, накопления и т. д.

Результаты. Рассмотрев общее состояние и развитие агропромышленного комплекса как Республики Дагестан, так и в целом по СКФО, делаем вывод, что самым важным условием для роста показателей пищевой и перерабатывающей промышленности является привлечение инвестиций за счет внедрения новых технологий и техники в производство, подготовка и использование высококвалифицированных кадров по применению научных достижений в области АПК на предприятиях, что, в свою очередь, будет способствовать росту конкурентоспособности отрасли.

Выводы. Техническая и технологическая модернизация сельского хозяйства, увеличение производительности труда, повышение урожайности сельскохозяйственных культур, а также продуктивности скота позволит создать конкурентоспособную, сырьевую базу в аграрном секторе Республики Дагестан, что является одним из основных условий стабильного развития перерабатывающей промышленности. Сегодня, используя мировой и передовой отечественный опыт, необходимо внедрять передовые технологии выращивания конечной продукции АПК. Перспективное развитие перерабатывающего блока АПК должно идти по интеграционной модели, по пути образования отраслевых компаний, холдингов, потребительских кооперативов по производству, переработке и реализации.

Литература

1. Балияни К. М. Импортозамещение и продовольственная безопасность Республики Дагестан / К. М. Балияни // Региональные проблемы преобразования экономики. - 2017. - № 1 (75). - C. 39-45.

2. Балияни К. М. Основные факторы эффективного использования ресурсного потенииала сельских территорий Республики Дагестан / К. М. Балияни, А. З. Джамбулатова, С. В. Дохолян, Ю. Д. Умавов // Экономика устойчивого развития. - 2019. - № 1 (37). - С. 92-96. 
3. Буклет «Показатели финансово-хозяйственной деятельности сельскохозяйственных предприятий за 2017 год». Министерство сельского хозяйства и продовольствия РД. - Махачкала. - 2018.

4. Бухвальд Е. М. Планирование индустриального развития отсталых территорий России: от первого плана до современных стратегий (на примере Республики Дагестан) / Е. М. Бухвальд, Г. И. Идзиев // Региональные проблемы преобразования экономики. - 2019. - № 3 (101). - С. $20-27$.

5. Киреева Н. Импортозамещение как стратегия достижения продовольственной безопасности России: проблемы, пути решения // Н. Киреева, А. Сухорукова // Международный сельскохозяйственный журнал. - № 4. 2015.

6. Курбанов К. К. Диспропориии в АПК Северо-Кавказского федерального округа и их влияние на экономику сельских территорий / К. К. Курбанов, В. З. Петросяни // Региональные проблемы преобразования экономики. - 2014. - № 8 (46). - C. 107-112.

7. Курбанов К. К. Импортозамещение в АПК региона: проблемы и перспективы (по итогам Круглого стола «Актуальные вопросы развития АПК региона в условиях импортозамещения») // Региональные проблемы преобразования экономики. - 2016. - № 3. - С. 123-127.

8. Курбанов К. К. Инновачионное развитие регионального АПК: кластерный подход / К. К. Курбанов // Региональные проблемы преобразования экономики. - 2017. - № 4 (78). - С. 43-50.

9. Курбанов К. К. Использование ресурсного потенциала регионального АПК при решении задач импортозамещения / К. К. Курбанов, Р. А. Джабраилов, М. К. Махмудов // Региональные проблемы преобразования экономики. - 2016. - № 9 (71). - С. 43-49.

10. Курбанов К. К. Ключевые проблемы и модернизачия аграрного производства в субъектах СКФО/ К. К. Курбанов, В. 3 Петросяни // Региональные проблемы преобразования экономики. - 2013. - № 3 (37). - С. 124-129.

11. Мукаилов М. Д. Проблемы и приоритетные направления развития интеграционных процессов в агропромышленном комплексе Республики Дагестан / М. Д. Мукаилов, К. К. Курбанов // Проблемы развития АПК региона. - 2017. - № 4 (32). - С. 176-181.

12. Россия в цииррах. 2017: краткий статистический сборник / Росстат. - М., 2018. - 558 c.

13. Социально-экономическое положение Северо-Кавказского федерального округа в 2018 году. ФСГС. - М. - 2019.

14. Юнусова П. С. Трансформачия отраслевой структуры в аграрном секторе экономики СКФО / П. С. Юнусова, С. В. Дохолян // Региональные проблемы преобразования экономики. ИСЭИ ДНЦ РАН. - Махачкала, 2017. - № 3 (77). - C. 19-26.

15. [Электронный ресурс]. Режим доступа: http://economy.gov.ru/minec/contacts, свободный. - Загл. с экрана. 16. Argyris Ch. Management and Organizational Development. New-York, 1989.-P. 35-41.

17. Armstrong H., Taylor J. Regional Economics and Policy. N.-Y.,1993.

18. Twiss B. Managing Technological innovation. Pitman Publishing. 4th Edition. 1992.

\section{References:}

1. Baliyanc K. M. Importozameshchenie i prodovol'stvennaya bezopas-nost' Respubliki Dagestan / K. M. Baliyanc // Regional'nye problemy preobrazovaniya ekonomiki. - 2017. - № 1 (75). - S. 39-45.

2. Baliyanc K. M. Osnovnye faktory effektivnogo ispol'zovaniya resursnogo potenciala sel'skih territorij Respubliki Dagestan / K. M. Baliyanc, A. Z. Dzhambulatova, S. V. Doholyan, YU. D. Umavov // Ekonomika ustojchivogo razvitiya. - 2019. - № 1 (37). - S. 92-96.

3. Buklet «Pokazateli finansovo-hozyajstvennoj deyatel'nosti sel'-skohozyajstvennyh predpriyatij za 2017 god». Ministerstvo sel'skogo hozyaj-stva i prodovol'stviya RD. - Mahachkala. - 2018.

4. Buhval'd E. M. Planirovanie industrial'nogo razvitiya otstalyh territorij Rossii: ot pervogo plana do sovremennyh strategij (na primere Respubliki Dagestan) / E. M. Buhval'd, G. I. Idziev // Regional'nye problemy preobrazovaniya ekonomiki. - 2019. - № 3 (101). - S. 20-27.

5. Kireeva N. Importozameshchenie kak strategiya dostizheniya prodovol'stvennoj bezopasnosti Rossii: problemy, puti resheniya // N. Kireeva, A. Suhorukova // Mezhdunarodnyj sel'skohozyajstvennyj zhurnal. - № 4. - 2015.

6. Kurbanov K. K. Disproporcii v APK Severo-Kavkazskogo federal'nogo okruga i ih vliyanie na ekonomiku sel'skih territorij / K. K. Kurbanov, V. Z. Petrosyanc // Regional'nye problemy preobrazovaniya ekonomiki. - 2014. - № 8 (46). $-S .107-112$.

7. Kurbanov K. K. Importozameshchenie $v$ APK regiona: problemy i perspektivy (po itogam Kruglogo stola "Aktual'nye voprosy razvitiya APK regiona v usloviyah importozameshcheniya») // Regional'nye problemy preobrazovaniya ekonomiki. - 2016. - № 3. - S. 123-127.

8. Kurbanov K. K. Innovacionnoe razvitie regional'nogo APK: kla-sternyj podhod / K. K. Kurbanov // Regional'nye problemy preobrazovaniya ekonomiki. - 2017. - № 4 (78). - S. 43-50.

9. Kurbanov K. K. Ispol'zovanie resursnogo potenciala regional'nogo APK pri reshenii zadach importozameshcheniya / K. K. Kurbanov, R. A. Dzhabrailov, M. K. Mahmudov // Regional'nye problemy preobrazovaniya ekonomiki. 2016. - № 9 (71). - S. 43-49.

10. Kurbanov K. K. Klyuchevye problemy i modernizaciya agrarnogo proizvodstva v subëktah SKFO/K. K. Kurbanov, V. Z Petrosyanc // Regional'nye problemy preobrazovaniya ekonomiki. - 2013. - № 3 (37). - S. 124-129.

11. Mukailov M. D. Problemy i prioritetnye napravleniya razvitiya integracionnyh processov v agropromyshlennom komplekse Respubliki Dagestan / M. D. Mukailov, K. K. Kurbanov // Problemy razvitiya APK regiona. - 2017. - № 4 (32). - S. 176-181.

12. Rossiya v cifrah. 2017: kratkij statisticheskij sbornik/Ros-stat. - M., 2018. - 558 s.

13. Social'no-ekonomicheskoe polozhenie Severo-Kavkazskogo fede-ral'nogo okruga v 2018 godu. FSGS. - M. - 2019.

14. YUnusova P. S. Transformaciya otraslevoj struktury v agrarnom sektore ekonomiki SKFO / P. S. YUnusova, S. V. Doholyan // Regional'nye problemy preobrazovaniya ekonomiki. ISEI DNC RAN. - Mahachkala, 2017. - № 3 (77). S. 19-26.

15. [Elektronnyj resurs]. Rezhim dostupa: http://economy.gov.ru/minec/contacts, svobodnyj. - Zagl. s ekrana.

16. Argyris Ch. Management and Organizational Development. New-York, 1989.-P. 35-41.

17. Armstrong N., Taylor J. Regional Economics and Policy. N. -Y.,1993.

18. Twiss V. Managing Technological innovation. Pitman Publishing. 4th Edition. 1992. 